Published in final edited form as:

Curr Heart Fail Rep. 2019 April ; 16(2): 57-66. doi:10.1007/s11897-019-0424-1.

\title{
Diuretic Resistance in Heart Failure
}

Richa Gupta, MD, MPH ${ }^{1}$, Jeffrey Testani, MD, MTR ${ }^{3}$, and Sean Collins, MD, MSc ${ }^{2}$

${ }^{1}$ Department of Cardiovascular Medicine, Vanderbilt University Medical Center, 1121 Medical Center Dr., Nashville, TN 37212

${ }^{2}$ Department of Emergency Medicine, Vanderbilt University Medical Center, 131321 st Ave. S, 703 Oxford House, Nashville, TN 37232

${ }^{3}$ Department of Cardiovascular Medicine, Yale Medical Center, PO Box 208017, New Haven, CT 06520

\section{Abstract}

Purpose of review: Diuretic resistance (DR) occurs along a spectrum of relative severity and contributes to worsening of acute heart failure (AHF) during an inpatient stay. This review gives an overview of mechanisms of DR with a focus on loop diuretics and summarizes the current literature regarding the prognostic value of diuretic efficiency and predictors of natriuretic response in AHF.

Recent findings: The pharmacokinetics of diuretics are impaired in chronic heart failure, but little is known about mechanisms of DR in AHF. Almost all diuresis after administration of a loop diuretic dose occurs in the first few hours after administration and within-dose DR can develop. Recent studies suggest that DR at the level of the nephron may be more important than defects in diuretic delivery to the tubule. Because loop diuretics induce natriuresis, urine sodium (UNa) concentration may serve as a functional, physiologic and direct measure for diuretic responsiveness to a given loop diuretic dose.

Summary: Identifying and targeting individuals with DR for more aggressive, tailored therapy represents an important opportunity to improve outcomes. A better understanding of the mechanistic underpinnings of DR in AHF is needed to identify additional biomarkers and guide future trials and therapies.

\footnotetext{
Open Access: This article is distributed under the terms of the Creative Commons Attribution 4.0 International License (http:// creativecommons.org/licenses/by/4.0/), which permits unrestricted use, distribution, and reproduction in any medium, provided you give appropriate credit to the original author(s) and the source, provide a link to the Creative Commons license, and indicate if changes were made.

Corresponding author: Sean Collins: 615-936-0253, sean.collins@ vumc.org.

Compliance with Ethics Guidelines

Conflict of Interest

Richa Gupta declares no conflicts of interest.

Human and Animal Rights and Informed Consent

This article does not contain any studies with human or animal subjects performed by any of the authors.

Papers of particular interest, published recently, have been highlighted as:

- Of importance

•• Of major importance
} 


\section{Keywords}

Acute heart failure; Loop diuretics; Diuretic resistance; Spot urine sodium; Biomarkers

\section{Introduction}

The prevalence of hypertension, chronic heart failure (HF), and chronic kidney disease are increasing, and cardiovascular disease is currently the most common cause of death and disability worldwide [1]. HF affects nearly 6 million people in the United States. In over one million annual hospital discharges, acute heart failure (AHF) is the primary diagnosis [2]. Development of congestion leading to AHF decompensation powerfully predicts poor patient outcome [3, 4]. Despite symptom improvement, at least $50 \%$ of patients experience no weight loss [5] and up to 50\% leave the hospital with residual congestion which predicts additional readmissions and higher mortality [3, 6-9].

Diuretic resistance (DR) has no single accepted definition, but the most frequently cited is "failure to decongest despite adequate and escalating doses of diuretics" $(10,11)$. DR is a relative term, as, there exists a broad range of diuretic efficiency (DE), defined as the efficiency with which a diuretic can facilitate diuresis and natriuresis, rather than the absolute dose of diuretic [12]. Relatively few patients are completely diuretic "nonresponsive," however, depending on the bar set, 20-50\% of hospitalized patients have a poor initial response to IV loop diuretics and are deemed "diuretic resistant [13]." While normal response to a diuretic has been defined as 3-4 L per $40 \mathrm{mg}$ of furosemide, diuretic resistant individuals exhibit impaired DE along a spectrum of relative severity $[11,13]$. DR in patients has been shown to contribute to worsening heart failure (WHF) during inpatient stay, prolonged lengths of stay, and likely increased mortality and the consumption of more resources relative to those who respond adequately to initial diuretic administration [14-16]. Identifying and targeting these individuals for more aggressive, tailored therapy thus represents an important opportunity to improve outcomes.

Diuretics are the cornerstone of AHF therapy. The therapeutic effect of diuretics is a function of loss of body sodium and fluid [17, 18]. Most AHF admissions are due to volume overload and treated with intravenous (IV) loop diuretics. There is, however, currently no consensus on adjustment of IV loop diuretic doses based on individual responses to initial diuretic. In fact, because diuretic dosing and response vary widely, many patients are left inadequately treated [7]. To reduce the prevalence of WHF and optimize treatment delivery, the individual response to diuretics must be predictable so DR can be readily recognized, and therapy can be intensified.

The scope of this review focuses specifically on the characteristics of loop diuretics. First, we will outline the mechanism and pharmacokinetics of these drugs, showing the majority of natriuresis occurs shortly after the administration of a loop diuretic dose. Next, we discuss the diuretic "braking" phenomenon and mechanisms of DR in AHF, highlighting the importance of intra-renal DR. We then discuss the concept of loop DE as it relates to quantifying diuretic responsiveness, describing the literature to date that has focused on early-response prediction, highlighting the use of urine sodium (UNa) as an objective 
measure of natriuresis following loop diuretic administration. Finally, we will review the limitations of current approaches to AHF management and raise important remaining questions which, if answered, may guide future direction in reducing congestion, readmission rates and cardiovascular mortality.

\section{Mechanism of loop diuretics}

The first opportunity for an adequate diuretic response hinges on pharmacokinetics or the effective delivery of loop diuretics to inhibit the Na-K-2Cl cotransporter (NKCC2), as shown in Figure 1, and subsequently on their ability to produce a natriuresis (pharmacodynamics). Diuretics are first absorbed into the bloodstream via the gut, and the kinetics of absorption of loop diuretics varies after ingestion [19, 20]. Oral bumetanide and torsemide are absorbed more completely and reproducibly than furosemide. Furosemide has been reported to have bioavailability ranging from 10-90\% (average 50\%), and a doubling of the furosemide dose is considered equivalent when changing from IV to oral. Furosemide absorption can vary over time, within and in between patients [18-20]. Food, gastric pH, gut perfusion and edema are all known or thought to influence absorption kinetics. Diuretics gain access to tubular fluid by active proximal secretion via organic anion transporters (OATs), a process dependent on renal blood flow and shown in Figure 1 [21]. Due to the high degree of protein binding there is minimal entry of loop diuretics into the tubular fluid by glomerular filtration, but rather the majority occurs via secretion by OATs [22].

\section{Pharmacokinetics and pharmacodynamics of loop diuretics in disease states}

Table 1 summarizes the commonly cited mechanisms of DR in the literature, although these have not been specifically investigated in AHF. Moreover, the relative importance of each of these mechanisms listed remains unclear; some mechanisms, such as renal tubular defects, are likely more important than others. Acidosis and hypoalbuminemia can exert an influence on drug delivery or pharmacokinetics, while, NSAIDs, reduced dietary salt intake and repeat administration of furosemide all diminish the renal tubular response to furosemide or pharmacodynamics [23]. Metabolic acidosis can depolarize the membrane potential of proximal tubule cells [24]. This has been hypothesized to decrease organic anion (OA) secretion, thus increasing plasma levels of $\mathrm{OA}$ and urate and impairing proximal tubule secretion of diuretics, which in turn decreases their delivery to the active sites in the nephron (18). Albumin potentiates proximal secretion of active furosemide and thus hypoalbuminemia may impair the uptake and secretion of active furosemide and enhance conversion to the drug's inactive form $[25,26]$. These mechanisms of enhanced furosemide metabolism and decreased tubular secretion of active diuretic, however, have never been studied in patients with AHF. In general, the pharmacokinetic effects of acidosis and albumin are relatively small and may be an irrelevant source of DR [27, 28].

Chronic kidney disease (CKD) and liver disease can influence drug delivery to the nephron or affect the degree to which the drug is potentiated [18]. Furosemide is metabolized to inactive glucuronide in the kidney, while bumetanide and torsemide are metabolized in the liver only [29]. This implies that in CKD, the relative potency of furosemide increases, 
enhancing natriuresis. Renal clearance of loop diuretics falls in parallel with glomerular filtration rate (GFR) due to decreased renal mass (reducing perfusion or renal blood flow and thus drug delivery) and accumulation of OAs such as blood urea nitrogen, which compete with proximal secretion of diuretic via OATs, further reducing diuretic availability at the site of action [16,21]. The maximal increase in fractional excretion of sodium produced by furosemide can be maintained well in CKD with a higher furosemide dose. The absolute response to diuretics, however, is still limited by the loss of nephrons which reduces the amount of absolute diuresis, even if each nephron is maximally excreting sodium. This is because renal blood flow is proportional to nephron mass [30, 31].

In chronic HF, the absorption kinetics of diuretics are impaired and these individuals, relative to people without HF, are diuretic resistant [20, 27, 32]. In HF, the loop diuretic dose-response curve is shifted down and to the right with attenuated response compared to normal subjects $[18,33]$. This log-linear relationship, illustrated in Figure 2, implies that it takes large increases in the dose of loop diuretic to achieve modest increases in diuresis. This relationship, however, has thus far not been studied in AHF. Recent literature suggests that defects at the level of the renal tubule are substantially more important than reduced diuretic delivery in determining DR in patients with AHF [34]. The authors of this study demonstrate two important points: 1) the amount of administered loop diuretic that actually reaches the tubule is highly variable between individual AHF patients and 2) urine diuretic concentration and delivery to the tubule is linearly related to serum concentration and the IV dose of diuretic. This suggests massive defects in drug secretion would be necessary to meaningfully alter DR. Thus, defects in drug delivery explain only a minor proportion of DR in an AHF population, implying that renal tubular defects are more important. Finally, AHF results from an imbalance in neurohormonal systems that regulate cardiac and renal function. Renin-angiotensin-aldosterone system (RAAS) and sympathetic nervous system (SNS) activation are traditionally implicated in the literature as mechanisms of diuretic resistance [11]. Through a myriad of mechanisms that evolved for the control of sodium and water balance, neurohormonal activation increases sodium retention, largely through direct effects on solute transport in various nephron segments [35].

It is for these reasons that higher doses of loop diuretic are often required to achieve maximal natriuretic response, which is generally substantially less than can be achieved in health or in CKD [36]. A key point to therapy in AHF is that while aggressive decongestion is associated with worsening renal function (WRF), survival appears to be paradoxically improved [37] The development of WRF, in some cases, suggests a high degree of decongestion is occurring, and those with preserved or improved renal function may be underdiuresed and leave the hospital with residual congestion. One post-hoc analysis showed that residual congestion at the time of WRF is prognostically important; patients with AHF who have WRF (creatinine increase of $\geq 0.3 \mathrm{mg} / \mathrm{dL}$ ) were shown to have longer average length of hospital stay and a greater risk of death or readmission for a cardiovascular or renal reason within 30 days of assessment if they exhibited significant congestion [38]. This suggests that patients that are incompletely decongested and develop WRF are overall a sicker, higher risk group. 
Lastly, pharmacogenetics may play a role in diuretic responsiveness. Studies have demonstrated certain polymorphisms can determine an individual's response to diuretics. Vormfelde et al, for instance, demonstrated that in 97 healthy white patients, diuretics exerted greater acute effect in subjects with polymorphisms in genes encoding the sodiumchloride cotransporter (NCC) and the beta subunit of ENaC (epithelial sodium channel transporters that are distal to $\mathrm{NKCC} 2$ ), but diminished effect in those with a polymorphism in the gamma-subunit of ENaC [39]. Another study identified female gender and polymorphisms in the gene encoding one of the organic anion transporters (OATP1B1) as a predictor of slower elimination of torsemide [40]. Finally, a more recent meta-analysis of the DOSE, CARESS and ROSE trials specifically studied patients with AHF to evaluate the impact of genetic variations in renal sodium reuptake transporters on the efficacy of furosemide therapy [41]. This study, however, was largely negative and found that none of the 6 primary variants in these genes were significantly associated with net fluid loss. Further investigation in this area is needed.

\section{Bioavailability of loop diuretics}

In disease states such as AHF, torsemide's increased oral bioavailability may make it a favorable drug of choice in the outpatient setting [20, 32, 33]. In AHF, furosemide is erratically bioavailable compared with bumetanide or torsemide. Recent literature suggests these differences between the drugs have clinical implications. One open label study found a $50 \%$ reduction in readmission to the hospital in patients with HF who were randomly assigned to receive torsemide rather than furosemide [42]. Another estimated that treatment with torsemide is more cost-effective than therapy with furosemide [43]. Long-term outcomes using torsemide compared with furosemide are currently being further studied in TRANSFORM (NCT03296813), a large-scale, randomized clinical effectiveness study of 6,000 patients recently hospitalized with HF.

\section{Duration of action of loop diuretics}

The duration of action of loop diuretics after oral dosing is short (generally only 2 to 4 hours), even when pharmacologic doses of drug remain in the tubular fluid. This results in abrupt, short-lived natriuresis, as DR at the level of the nephron, rather than pharmacokinetics, dictates the duration of action [44]. Notably, in a recent study with extended-release torsemide, severe within-dose development of DR was actually demonstrated [33].

Furthermore, multiple studies have demonstrated there are minimal to no differences between continuous and bolus dosing of furosemide despite the difference in pharmacokinetics between these two methods of delivery [45]. Notably, in the largest trial to date of infusion versus bolus (the DOSE trial), patients with the highest pre-admission diuretic dose (i.e., the patients with DR) had significantly lower diuresis with infusion compared to bolus $[6,46]$. These observations are notable in that there are profound pharmacokinetic advantages of continuous infusion of diuretic that are somehow being defeated by rapid development of DR. The constellation of observations reinforces the idea 
that interventions that target purely the pharmacokinetics of loop diuretics are unlikely to be fully successful if the response of the loop diuretic at the level of the kidney is ignored.

\section{Loop diuretic efficiency}

A growing body of literature suggests metrics of diuretic responsiveness can provide prognostic information beyond that provided by changes in weight, fluid balance or loop diuretic dose alone $[12,13]$. In this section, we further discuss the concept of loop DE and outline its ability to capture prognostic information.

Loop DE was originally defined as the net fluid loss per milligram of loop diuretic equivalent administered during AHF hospitalization [12]. Several studies have shown that DE can capture distinct prognostic information beyond raw fluid output and diuretic dose. In 2014, an analysis of a combined cohort of 1047 patients suggested DE was independently associated with survival after adjusting for baseline characteristics, diuretic dose and fluid output [12]. Diuretic dose did not retain independent prognostic information in this study and low DE had an equal if not worse prognosis in patients receiving lower doses of loop diuretics, arguing against the association between in-hospital high-dose loop diuretics and mortality being cause and effect. The authors additionally found no association between GFR and DE, suggesting renal function and drug delivery (or pharmacokinetics) does not drive DE in AHF, but rather it is the impact of cardiac function, renal function and volume status on the pharmacodynamics of loop diuretics (as previously described) that is more important.

The prognostic value of DE was also demonstrated using the CARESS, ROSE and DOSEHF trial data and outcomes [47]. In this study, DE was defined as total 72-hour fluid output per total loop diuretic dose, expressed as $40 \mathrm{mg}$ furosemide equivalents; survival was compared between patients with DE above versus below the median DE. Poor diuretic response was associated with low blood pressure, diabetes, long-term diuretic use, WRF and blood urea nitrogen, poorer New York Heart Association class and fewer signs of congestion. Lower DE was a marker of HF disease severity and was associated with reduced survival in this study as well.

\section{Diuretic braking and implications for AHF therapy}

"Diuretic braking" is a descriptive term for a reduction in diuretic response with repeated dosing. This is an observation rather than a mechanism, and the actual mechanistic underpinnings of this phenomenon, in health and disease, are poorly understood. Reduced response to diuretic has not been shown to have a clear, consistent association with detectable changes in plasma volume or renal hemodynamics, nor with class of diuretic [27].

The blunted natriuretic response to furosemide during repeated administration is attributed in the DR literature to several factors. Candidate mechanisms include reduced sodium chloride $(\mathrm{NaCl})$ delivery to the site of furosemide action, resulting in decreased inhibition of $\mathrm{NaCl}$ reabsorption by furosemide in the loop of Henle. It is unclear, however, if there is significant relevance to these mechanisms in humans. One study evaluated 128 patients with AHF receiving treatment with loop diuretics. The authors demonstrated that endogenous 
lithium clearance (a surrogate for proximal tubular sodium reabsorption) in AHF patients was no different compared to controls; most patients had a robust increase in lithium clearance following loop diuretic administration, indicating preserved sodium reabsorption response at the loop of Henle [28]. Another potential mechanism of DR has been shown in studies of rats receiving very high sodium diets. In these rats, several days of loop diuretic infusion caused structural hypertrophy of the distal convoluted tubule, connecting tubule and intercalated cells of the collecting duct [48]. These structural and functional adaptations result in an increase in the Na-K-ATPase activity and NCC expression in these downstream nephron segments, compensating for increased sodium exit from the loop of Henle induced by loop diuretics [49]. This leads to enhanced distal $\mathrm{NaCl}$ absorption, leading to inappropriate renal sodium retention in these animals that can persist for up to 2 weeks after cessation of diuretic therapy [49]. Rao et al, in the same study discussed above, showed some translation of this mechanism to humans. Again, by studying the fractional excretion of Lithium to assess proximal tubular and loop of Henle sodium handling, the authors showed that distal compensatory sodium reabsorption makes the largest relative contribution to diuretic-induced increase in the fractional excretion of sodium (FENa), and thus is a primary driver of DR [28].

These mechanisms of DR leave substantial uncertainty in clinical implications and recommendations for therapy in AHF. For instance, salt restriction to create a negative sodium chloride balance and compensate for post-diuretic salt retention is often a mainstay of inpatient therapy for AHF, even in the setting of receiving powerful loop diuretics [50]. Contemporary literature, however, would suggest that in AHF this may not be true; restriction of salt intake can be difficult in clinical practice and has been suggested to not be associated with improved outcomes [51]. A second mainstay of therapy during prolonged diuretic administration is to administer sequential nephron blockade by using additional classes of diuretic (for instance thiazides or carbonic anhydrase inhibitors) to overcome resistance and prevent post-diuretic sodium retention after cessation of loop diuretic activity. To date, however, studies to evaluate combination therapy in patients with AHF who have DR are scarce and inconclusive [11]. Some observational literature has actually suggested potential harm of early addition of thiazide diuretics [52]. However, a recently funded study should provide additional information about the combination of loop diuretics and carbonic anhydrase inhibitors [53]. Third, diuretics with more prolonged action or more frequent administration have been previously hypothesized to enhance $\mathrm{NaCl}$ loss by limiting time available for post-diuretic salt retention (for instance a continuous infusion). Again, this has never been objectively shown in evidence-based trial literature thus far. Lastly, there is no data to support that preventing or treating chloride-depletion alkalosis can enhance DE even though this has been proposed $[54,55]$. This idea, however, has not actually been tested.

\section{Measures of diuretic resistance}

In hospitalized patients, accurately accounting for actual fluid intake and elimination in AHF patients using measured output and/or standing weights can be labor-intensive, inaccurate and impractical. Real-time, objective measures of DE and natriuretic response may result in more individualized diuretic dosing to maximize AHF treatment. Over-activation of the RAAS/SNS activity in AHF stimulates sodium absorption. UNa, is thus a functional, 
physiologic, measurement that may represent a product of this activation in AHF. Because loop diuretics induce natriuresis, UNa concentration may serve as a direct measure for diuretic responsiveness that integrates multiple sources of DR and better reflects the response to a given loop diuretic dose. The inability to relieve congestion as predicted by sodium output may thus indicate more advanced disease.

A growing body of literature suggests that as an integrative measure of diuretic resistance, $\mathrm{UNa}$ can predict short term responsiveness to IV loop diuretics in patients with AHF. To date, several studies (summarized in Table 2) have been published that support the utility and value of UNa measurement. In 2014, a study of 52 patients with AHF suggested high spot UNa concentration assessed at steady state during continuous infusion of furosemide was associated with volume of urine output (UOP) and fewer adverse events [56]. This study suggests a strong correlation between $\mathrm{UNa}$ and DE in the setting of loop diuretic use. In a subsequent study, $\mathrm{UNa}>60 \mathrm{mmol} / \mathrm{L}$ measured at day 3 of a hospitalization for AHF was found to be associated with improved 180-day outcomes of AHF hospitalization and cardiovascular mortality [57]. Finally, a recently published study found that patients hospitalized with AHF with low spot UNa concentration ( $\leq 60 \mathrm{mmol} / \mathrm{L}$ ) after first IV diuretic administration are at increased risk for incomplete decongestion and adverse events compared to patients with intact natriuresis [58].

Further investigations (Table 2) have focused on practical methods to rapidly predict diuretic response. A prospective study of 50 patients with AHF used meticulously-collected 6-hour urine collections to quantify cumulative sodium output and derive an equation to predict net sodium output using a spot urine sample obtained 1 or 2 hours after loop diuretic administration [59]. The study found an excellent correlation between cumulative $\mathrm{UNa}$ output and predicted UNa output at 6 hours with application of this equation to $\mathrm{UNa}$ measurements collected 1 and 2 hours after IV diuretic administration. Other parameters such as sodium output, fluid output, weight change, UNa concentration, fractional excretion of sodium, and diuretic dose all had weaker correlations than that predicted from the equation. Thus, poor natriuretic response (defined as a cumulative sodium output $<50 \mathrm{mmol}$ ) could be accurately predicted with this equation. More recently, a study of 176 patients with AHF receiving IV furosemide investigated whether a single spot UNa measured at first void and at 3 hours in the outpatient setting could predict initial response [60]. The study suggested higher UNa predicted UOP after adjusting for age, BUN and GFR. It was also associated with a lower risk of hospitalization or ED visit in the subsequent 30 days even after adjusting for systolic blood pressure, hemoglobin and urine volume. The authors further identified cutoffs of a spot $\mathrm{UNa}$ in first voided urine after diuretic administration that was greater than $65 \mathrm{mmol}$ and UOP greater than $1.2 \mathrm{~L}$ to be associated with a significantly lower risk of 30-day hospitalization with this algorithm. Finally, a prospective study of the value of spot urine electrolytes 1 hour after first dose of diuretic upon ED presentation was conducted in 61 patients [61]. Urine electrolytes were measured and patients were followed during their hospitalization for WHF, defined as persistent or worsening AHF symptoms requiring intensification of AHF therapy during the first five days of hospitalization. The investigators showed that $\mathrm{UNa}$ at one hour $<35.4 \mathrm{mEq} / \mathrm{L}$ was $100 \%$ sensitive for predicting WHF and those with WHF had lower UNa and UOP at 1 hour and a longer inpatient length of stay. 
In summary, spot UNa concentration can add information beyond empiric response to diuretic infusion or other clinical variables. UNa is a marker of natriuresis that is easily measurable, readily available and reliably prognostic. Further study of urine chloride is also warranted for similar reasons.

\section{Future Directions}

The aforementioned prospective studies suggest spot $\mathrm{UNa}$ is a readily available measure of natriuresis and could be used to guide AHF therapy [62]. However, randomized trials are needed to determine the incremental benefit of this approach relative to standard clinical management. Furthermore, additional investigation of biomarkers and molecular determinants of diuretic response beyond UNa are needed to determine their role in predicting HF, HF readmission and cardiovascular death; little to no investigation exists in this area. These studies, however, might lay the foundation for further investigations evaluating alternative diuretic strategies and their impact on ENaC expression and DE. Lastly, more accurate measures of decongestion, such as the clinical congestion score, should be utilized in the methodology of future trials to quantify the impact of AHF therapy during hospitalization and at the time of discharge [3]. Other objective measures of decongestion need to be further explored as we determine the optimal method of decongestion. Studies of changes in blood volume, for instance, suggest this may be another objective measure of decongestion [63].

\section{Conclusions and recommendations}

Our review of DR in AHF lends itself to a few points that highlight key clinical implications of AHF management. First, almost all diuresis after administration of a loop diuretic dose occurs in the first few hours after administration and there is even within-dose DR that develops. In disease states like CKD and AHF, this resistance occurs as a direct result of the disease. Second, identifying patients anticipated to have low DE on presentation to the hospital or in the ED can facilitate triage of patients less likely to be responsive to therapy, shorten time to first diuretic dose, and guide rapid escalation of diuretic strategies. Identification of these poor-responders can also allow for their selective enrollment in RCTs for new therapies. Finally, evidence-based guideline recommendations for AHF therapy in the hospital setting are currently lacking and there is extensive interest in determining the optimal approach to initial therapy. While response to AHF therapy remains poorly defined, it is likely that greater decongestion improves outcomes.

We suggest measures of UNa may be a tool that can help optimize diuretic dosing and efficiency. Sodium and water retention due to inadequate natriuresis and diuresis are hallmarks of AHF. Poor gut absorption of orally administered loop diuretics, decreased diuretic delivery to the site of action and renal tubular compensatory hypertrophy all lead to a diminished effect of diuretics, resulting in impaired UNa excretion and the diuretic braking phenomenon, thus contributing to resistance in patients with AHF. UNa is an objective measure of natriuresis that can be measured within an hour or two of loop diuretic therapy; assays of biomarker activity show similar promise. This supports the design of a randomized controlled trial evaluating the use of these objective measures of spot UNa-directed and/or 
biomarker-directed diuresis to improve clinical symptoms and decrease WHF, postdischarge AHF readmission and cardiovascular mortality. Such a study would inform clinical practice and could lead to a protocolized diuretic regimen based on these dynamic changes to quickly optimize decongestion. Finally, UNa and genetic or molecular biomarkers are just examples of potential measurable tools that may guide diuretic therapy, however in reality, little is known about mechanisms of DR. Recent literature presented in this review suggests that much of this resistance occurs at the level of the nephron, which must not be ignored. Ultimately, a better understanding of the mechanistic underpinnings of DR in AHF is needed to inform the design of future trials evaluating AHF therapy.

\section{Acknowledgments}

Jeffrey Testani received consultancy fees and/or research grants from: AstraZeneca, Boehringer Ingelheim, Sanofi, Abbott, FIRE1, Sequana Medical, Otsuka, Bristol Myers Squibb, Reprieve Medical, Cardionomic and 3ive labs.

Sean Collins received consultancy fees and/or research grants from Novartis, Vixiar, Ortho Clinical, NIH, AHRQ, PCORI, DOD, AHA, and CREAVO.

\section{References}

1. Wang H, Dwyer-Lindgren L, Lofgren KT, Rajaratnam JK, Marcus JR, Levin-Rector A, et al. Agespecific and sex-specific mortality in 187 countries, 1970-2010: a systematic analysis for the Global Burden of Disease Study 2010. Lancet 2013;380:2071-94.

2. Roger VL, Go AS, Lloyd-Jones DM, Adams RJ, Berry JD, Brown TM, et al. Heart disease and stroke statistics-2011 update: a report from the American Heart Association. Circulation 2011;123:e18-e209. [PubMed: 21160056]

3. Ambrosy AP, Pang PS, Khan S, Konstam MA, Fonarow GC, Traver B, et al. Clinical course and predictive value of congestion during hospitalization in patients admitted for worsening signs and symptoms of heart failure with reduced ejection fraction: findings from the EVEREST trial. Eur Heart J 2013;34:835-43. [PubMed: 23293303]

4. Gheorghiade M, Follath F, Ponikowski P, Barsuk JH, Blair JE, Cleland JG, et al. Assessing and grading congestion in acute heart failure: a scientific statement from the acute heart failure committee of the Heart Failure Association of the European Society of Cardiology and endorsed by the European Society of Intensive Care Medicine. Eur J Heart Fail 2010;12:423-33. [PubMed: 20354029]

5. Ambrosy AP, Cerbin LP, Armstrong PW, Butler J, Coles A, DeVore AD, et al. Body weight change during and after hospitalization for acute heart failure: patient characteristics, markers of congestion, and outcomes: findings from the ASCEND-HF Trial. JACC Heart Fail 2017;5:1-13. [PubMed: 28034373]

6. Lala A, McNulty SE, Mentz RJ, Dunlay SM, Vader JM, AbouEzzeddine OF, et al. Relief and recurrence of congestion during and after hospitalization for acute heart failure: insights from diuretic optimization strategy evaluation in acute decompensated heart failure (DOSE-AHF) and cardiorenal rescue study in acute decompensated heart failure (CARESS-HF). Circ Heart Fail 2015;8:741-8. [PubMed: 26041600]

7. Yancy CW, Fonarow GC, ADHERE Scientific Advisory Committee. Quality of care and outcomes in acute decompensated heart failure: the ADHERE registry. Current Heart Fail Rep 2004;1:121-8.

8. Kociol RD, McNulty SE, Hernandez AF, Lee KL, Redfield MM, Braunwald E, et al. Markers of decongestion, dyspnea relief, and clinical outcomes among patients hospitalized with acute heart failure. Circ Heart Fail 2013;6:240-5. [PubMed: 23250981]

9. Mentz RJ, Kjeldsen K, Rossi GP, Voors AA, Cleland JG, Anker SD, et al. Decongestion in acute heart failure. Eur J Heart Fail 2014;16:471-82. [PubMed: 24599738]

10. Ellison DH. Diuretic therapy and resistance in congestive heart failure. Cardiology 2001;96:13243. [PubMed: 11805380] 
11. Ter Maaten JM, Valente MA, Damman K, Hillege HL, Navis G, Voors AA. Diuretic response in acute heart failure-pathophysiology, evaluation, and therapy. Nat Rev Card 2015;12:184-92.

12•. Testani JM, Brisco MA, Turner JM, Spatz ES, Bellumkonda L, Parikh CR, et al. Loop diuretic efficiency: a metric of diuretic responsiveness with prognostic importance in acute decompensated heart failure. Circ Heart Fail 2014;7:261-70. [PubMed: 24379278] This was the first study to define the concept of diuretic efficiency (DE) or the efficiency with which diuretic can facilitate diuresis and natriuresis. This study also showed that DE can capture prognostic information beyond raw fluid output or diuretic dose and is independently associated with survival. The authors also found no association between glomerular filtration rate and DE, suggesting that renal function and drug delivery or pharmacokinetics may be less important drivers of DE.

13•. Valente MA, Voors AA, Damman K, Van Veldhuisen DJ, Massie BM, O’Connor CM, et al. Diuretic response in acute heart failure: clinical characteristics and prognostic significance. Eur Heart J 2014;35:1284-93. [PubMed: 24585267] This was one of the first studies to show that worse diuretic response was associated with more advanced heart failure among other adverse clinical conditions and predicts mortality and heart failure rehospitalizations.

14. O'Connor CM, Starling RC, Hernandez AF, Armstrong PW, Dickstein K, Hasselblad V, et al. Effect of nesiritide in patients with acute decompensated heart failure. N Engl J Med 2011;365:3243. [PubMed: 21732835]

15. Teerlink JR, Cotter G, Davison BA, Felker BA, FIlippatos G, Greenberg BH, et al. Serelaxin, recombinant human relaxin-2, for treatment of acute heart failure (RELAX-AHF): a randomised, placebo-controlled trial. Lancet 2013;381:29-39. [PubMed: 23141816]

16. Packer M, O’Connor C, McMurray JJ, Wittes J, Abraham WT, Anker SD, et al. Effect of Ularitide on Cardiovascular Mortality in Acute Heart Failure. N Engl J Med 2017;376:1956-64. [PubMed: 28402745]

17. Vasavada N, Agarwal R. Role of excess volume in the pathophysiology of hypertension in chronic kidney disease. Kidney Int 2003;64:1772-79. [PubMed: 14531810]

18. Hoorn EJ, Wilcox CS, Ellison DH. Diuretics. In: Skorecki K, Chertow GM, Marsden PA, Taal MW, Yu ASL. Brenner and Rector's The Kidney $10^{\text {th }}$ ed. Philadelphia: Elsevier; 2016:1702$1733 .^{\text {th }}$

19. Murray MD, Haag KM, Black PK, Hall SD, Brater DC, et al.: Variable furosemide absorption and poor predictability of response in elderly patients. Pharmacotherapy 1997;17:98-106. [PubMed: 9017769]

20. Vargo DL, Kramer WG, Black PK, Smith WB, Serpas T, Brater DC, et al. Bioavailability, pharmacokinetics, and pharmacodynamics of torsemide and furosemide in patients with congestive heart failure. Clin Pharmacol Ther 1995;57:601-09. [PubMed: 7781259]

21. Sweet DH, Bush KT, Nigam SK. The organic anion transporter family: from physiology to ontogeny and the clinic. Am J Physiol Renal Physiol 2001;281:F197-205. [PubMed: 11457711]

22. Uwai Y, Saito H, Hashimoto Y. Inui KI. Interaction and transport of thiazide diuretics, loop diuretics, and acetazolamide via rat renal organic anion transporter rOAT1. J Pharmacol Exp Ther 2000;295:261-65. [PubMed: 10991988]

23. Chennavasin P, Seiwell R, Brater DC. Pharmacokinetic-dynamic analysis of the indomethacinfurosemide interaction in man. J Pharmacol Exp Ther 1980;215:77-81. [PubMed: 7452492]

24. Krick W, Wolff NA, Burckhardt G. Voltage-driven p-aminohippurate, chloride, and urate transport in porcine renal brush-border membrane vesicles. Pflügers Arch 2000; 441:125-32. [PubMed: 11205051]

25. Jackson CE, Solomon SD, Gerstein HC, Zetterstrand S, Olofsson B, Michelson EL, et al. Albuminuria in chronic heart failure: prevalence and prognostic importance. Lancet 2009;374:543-50. [PubMed: 19683640]

26. Besseghir K, Mosig D, Roch-Ramel F. Facilitation by serum albumin of renal tubular secretion of organic ions. Am J Physiol 1989;256:F475-84. [PubMed: 2466412]

27. Loon NR, Wilcox CS, Unwin RJ. Mechanism of impaired natriuretic response to furosemide during prolonged therapy. Kidney Int 1989:36;682-9. [PubMed: 2811065] 
28. Rao VS. Planavasky N, Hanberg JS, Ahmad T, Brisco-Bacik MA, Wilson FP, et al. Compensatory distal reabsorption drives diuretic resistance in human heart failure. J Am Soc Nephrol 2017;28:3414-24. [PubMed: 28739647]

29. Wilcox CS. New insights into diuretic use in patients with chronic renal disease. J Am Soc Nephrol 2002;13:798-805. [PubMed: 11856788]

30. Rose HJ, O’Malley K, Pruitt AW. Depression of renal clearance of furosemide in man by azotemia. Clin Pharmacol Ther 1997;21:141-6.

31. Brater DC, Anderson SA, Brown-Cartwright D. Response to furosemide in chronic renal insufficiency: rationale for limited doses. Clin Pharmacol Ther 1986;40:134-9. [PubMed: 3731676]

32. Sica DA. Pharmacotherapy in congestive heart failure: drug absorption in the management of congestive heart failure: loop diuretics. Congest Heart Fail 2003;9:287-92. [PubMed: 14564148]

33•. Shah S, Pitt B, Brater DC, Feig PU, Shen W, Khwaja FS, et al. Sodium and fluid excretion with torsemide in healthy subjects is limited by the short duration of diuretic action. J Am Heart Assoc 2017;6:e006135. [PubMed: 28982672] This study demonstrated the development of severe within-dose development of diuretic resistance (DR), providing some of the first evidence to suggest that DR at the level of the nephron, rather than pharmacokinetics, is important in dictating diuretic duration of action.

34•. Ter Maaten JM, Rao VS, Hanberg JS, Wilson FP, Bellumkonda L, Assefa M, et al. Renal tubular resistance is the primary driver for loop diuretic resistance in acute heart failure. Eur J Heart Fail 2017;19:1014-22. [PubMed: 28105769] This study highlights the importance of renal tubular defects in driving DR in acute heart failure.

35. Kazory A Emergence of blood urea nitrogen as a biomarker of neurohormonal activation in heart failure. Am. J. Cardiol 2010:106;694-700. [PubMed: 20723648]

36. Verbrugge FH, Nijst P, Dupont M, Penders, Tang WH, Mullens W, et al.: Urinary composition during decongestive treatment in heart failure with reduced ejection fraction. Circ Heart Fail 2014;7:766-72. [PubMed: 25037309]

37. Testani JM, Chen J, McCauley BD, Kimmel SE, Shannon RP. Potential effects of aggressive decongestion during the treatment of decompensated heart failure on renal function and survival. Circulation 2010;122:265-72. [PubMed: 20606118]

38. Metra M, Cotter G, Senger S, Edwards C, Cleland JG, Ponikowski P, et al. Prognostic significance of creatinine increases during an acute heart failure admission in patients with and without residual congestion: a post hoc analysis of the PROTECT data. Circ Heart Fail 2018;11:e004644. [PubMed: 29748350]

39. Vormfelde SV, Sehrt D, Toliat MR, Schirmer M, Meineke I, Tzvetkov M, et al.: Genetic variation in the renal sodium transporters $\mathrm{NKCC} 2, \mathrm{NCC}$, and $\mathrm{ENaC}$ in relation to the effects of loop diuretic drugs. Clin Pharmacol Ther 2007;82:300-9. [PubMed: 17460608]

40. Werner U, Werner D, Heinbuchner S, Graf B, Ince H, Kische S, et al.: Gender is an important determinant of the disposition of the loop diuretic torasemide. J Clin Pharmacol 2010;50:160-8. [PubMed: 19934028]

41. de Denus S, Rouleau JL, Mann DL, Huggins GS, Cappola TP, Shah SH, et al. A pharmacogenetic investigation of intravenous furosemide in decompensated heart failure: a meta-analysis of 3 clinical trials. Pharmacogenomics J 2017;17:192-200. [PubMed: 26927285]

42. Murray MD, Deer MM, Ferguson JA, Dexter PR, Bennett SJ, Perkins SM, et al. Open-label randomized trial of torsemide compared with furosemide therapy for patients with heart failure. Am J Med 2001;111;513-20. [PubMed: 11705426]

43. Stroupe KT, Forthofer MM, Brater DC, Murray MD. Healthcare costs of patients with heart failure treated with torsemide or furosemide. Pharmacoeconomics 2000;17:429-40. [PubMed: 10977385]

44. Ferguson JA, Sundblad KJ, Becker PK, Gorski JC, Rudy DW, Brater DC. Role of duration of diuretic effect in preventing sodium retention. Clin Pharmacol Ther 1997;62:203-8. [PubMed: 9284857]

45. Wu MY, Chang NC, Su CL, Hsu YH, Chen TW, Lin YF, et al. Loop diuretic strategies in patients with acute decompensated heart failure: a meta-analysis of randomized controlled trials. J Crit Care 2014;29:2-9. [PubMed: 24331943] 
46. Felker GM, Lee KL, Bull DA, Redfield MM, Stevenson LW, Goldsmith SR, et al. Diuretic strategies in patients with acute decompensated heart failure. N Engl J Med 2011;364:797-805. [PubMed: 21366472]

47•. Kiernan MS, Stevens SR, Tang WHW, Butler J, Anstrom K, Birati EY, et al. Determinants of diuretic responsiveness and associated outcomes during acute heart failure hospitalization: an analysis from the NHLBI Heart Failure Network clinical trials. J Card Fail 2018;24:428-38. [PubMed: 29482026] This study defined DE as total 72-hour fluid output per total loop diuretic dose; lower DE was a marker of heart failure disease severity and associated with reduced survival. Poor diuretic response was associated with poor clinical markers.

48. Garg LC, Kapturczak M. Renal compensatory response to hydrochlorothiazide changes Na-KATPase in distal nephron. In Puschett JB, Greenberg A. Diuretics II: chemistry, pharmacology, and clinical applications: proceedings of the Second International Conference on Diuretics, held June 22-27, 1986, Cascais, Portugal, New York, 1987, Elsevier Science Ltd 188-194.

49. Kaissling B, Bachmann S, Kriz W. Structural adaptation of the distal convoluted tubule to prolonged furosemide treatment. Am J Physiol 1985;248:F374-81. [PubMed: 3976898]

50. Doukky R, Avery E, Mangla A, Collado FM, Ibrahim Z, Poulin MF, et al. Impact of dietary sodium restriction on heart failure outcomes. JACC Heart Fail 2016;4:24-35 [PubMed: 26738949]

51. Wilcox CS, Mitch WE, Kelly RA, Skorecki K, Meyer TW, Friedman PA, et al. Response of the kidney to furosemide. I. Effects of salt intake and renal compensation. J Lab Clin Med 1983;102:450-8. [PubMed: 6886524]

52. Brisco-Bacik MA, Ter Maaten JM, Houser SR, Verdage NA, Rao V, Ahmad T, et al. Outcomes associated with a strategy of adjuvant metolazone or high-dose loop diuretics in acute decompensated heart failure: a propensity analysis. J Am Heart Assoc 2018;7:e009149. [PubMed: 30371181]

53. Mullens W, Verbrugge FH, Nijst P, Martens P, Tartaglia K, Theunissen E, et al. Rationale and design of the ADVOR (Acetazolamide in Decompensated Heart Failure with Volume Overload) trial. Eur J Heart Fail 2018;20:1591-1600. [PubMed: 30238574]

54. Wilcox CS, Loon NR, Kanthawatana S, Pham MA, Cannizzaro R. Generation of alkalosis with loop diuretics: roles of contraction and acid excretion. J Nephrol 1991;2:81-7.

55. Loon NR, Wilcox CS: Mild metabolic alkalosis impairs the natriuretic response to bumetanide in normal human subjects. Clin Sci 1998;94:287-92. [PubMed: 9616263]

56•. Singh D, Shrestha K, Testani JM, Verbrugge FH, Dupont M, Mullens W, et al. Insufficient natriuretic response to continuous intravenous furosemide is associated with poor long-term outcomes in acute decompensated heart failure. J Card Fail 2014;20:392-9. [PubMed: 24704538] Describes urinary sodium (UNa) as a predictor of clinical outcomes or natriuretic response. Described in text and Table 2.

57•. Ferreira JP, Girerd N, Medeiros PB, Santos M, Carvalho HC, Bettencourt P, et al. Spot urine sodium excretion as prognostic marker in acutely decompensated heart failure: the spironolactone effect. Clin Res Cardiol 2016;105:489-507. [PubMed: 26615605] Describes UNa as a predictor of clinical outcomes or natriuretic response. Described in text and Table 2.

58• Luk A, Groarke JD, Desai AS, Mahmood SS, Gopal DM, Joyce E, et al. First spot urine sodium after initial diuretic identifies patients at high risk for adverse outcome after heart failure hospitalization. American Heart J 2018;203:95-100.Describes UNa as a predictor of clinical outcomes or natriuretic response. Described in text and Table 2.

59•. Testani JM, Hanberg JS, Cheng S, Rao V, Onyebeke C, Laur O, et al. Rapid and highly accurate prediction of poor loop diuretic natriuretic response in patients with heart failure. Circ Heart Fail 2016;9:e002370. [PubMed: 26721915] Describes UNa as a predictor of clinical outcomes or natriuretic response. Described in text and Table 2.

60•. Brinkley DM, Burpee LJ, Chaudhry S, Smallwood JA, Lindenfeld J, Lakdawala NK, et al. Spot urine sodium as triage for effective diuretic infusion in an ambulatory heart failure unit. J Card Fail 2018;24:349-54. [PubMed: 29410227] Describes UNa as a predictor of clinical outcomes or natriuretic response. Described in text and Table 2.

61 • Collins SC, Jenkins CA, Baughman A, Miller KF, Storrow A, Han JH, et al. Early urine electrolyte patterns are associated with in-hospital worsening heart failure in emergency 
department patients with acute heart failure. ESC Heart Fail 2018.Describes UNa as a predictor of clinical outcomes or natriuretic response. Described in text and Table 2.

62•. Mullens W, Damman K, Harjola V, Mebazaa A, Brunner-La Rocca H, Martens P, et al. The use of diuretics in heart failure with congestion - a position statement from the Heart Failure Association of the European Society of Cardiology. Eur J Heart Fail 2019. doi:10.1002/ejhf. 1369.This is a recent, important expert opinion/position paper focusing on the practical use of diuretics in AHF with congestion.

63. Strobeck JE, Feldschuh J, Miller WL. Heart failure outcomes with volume-guided management. JACC Heart Fail 2018;6:940-8. [PubMed: 30316941] 

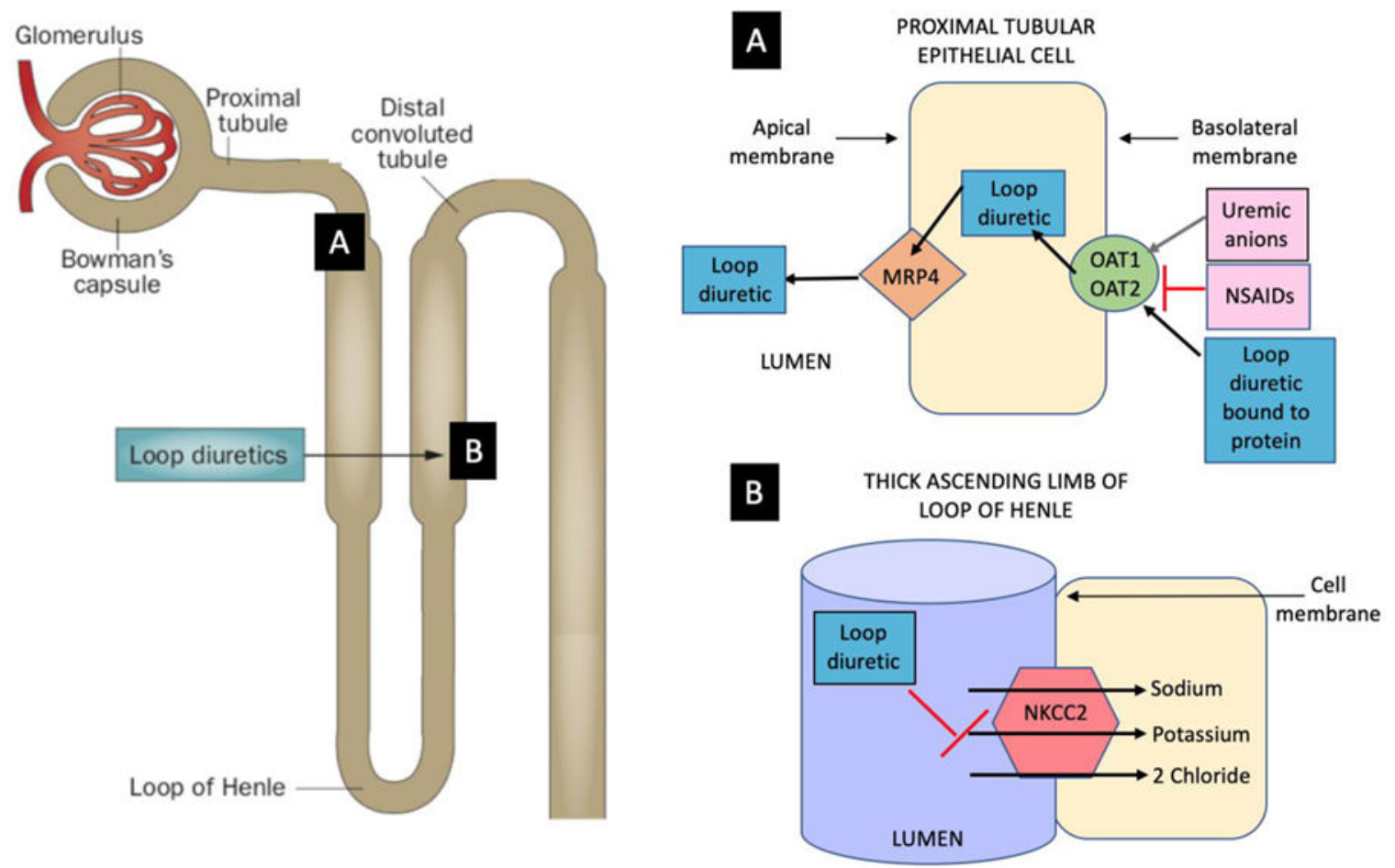

Fig 1.

Diuretic secretion by the proximal tubule and diuretic action on the Loop of Henle. A. Proximal convoluted tubule: After translocation into the proximal tubule cell, the loop diuretic is then secreted across the basolateral or luminal membrane by voltage-driven organic anion transporters (OAT1 and OAT2) and at the apical membrane by multidrug resistance-associated protein 4 (MRP4) and others. B. Thick ascending limb of the loop of Henle: The primary action of loop diuretics occurs here on the luminal membrane where an electroneutral $\mathrm{Na}-\mathrm{K}-2 \mathrm{Cl}$ (NKCC2) is located. This cotransporter mediates sodium and chloride movement across the apical membrane. Loop diuretics bind to the NKCC2 from the luminal surface to block the reabsorption of sodium and chloride across the apical membrane via this transporter. The tubular lumen becomes more hypertonic and the interstitium less so, diminishing the osmotic gradient required for water reabsorption. 


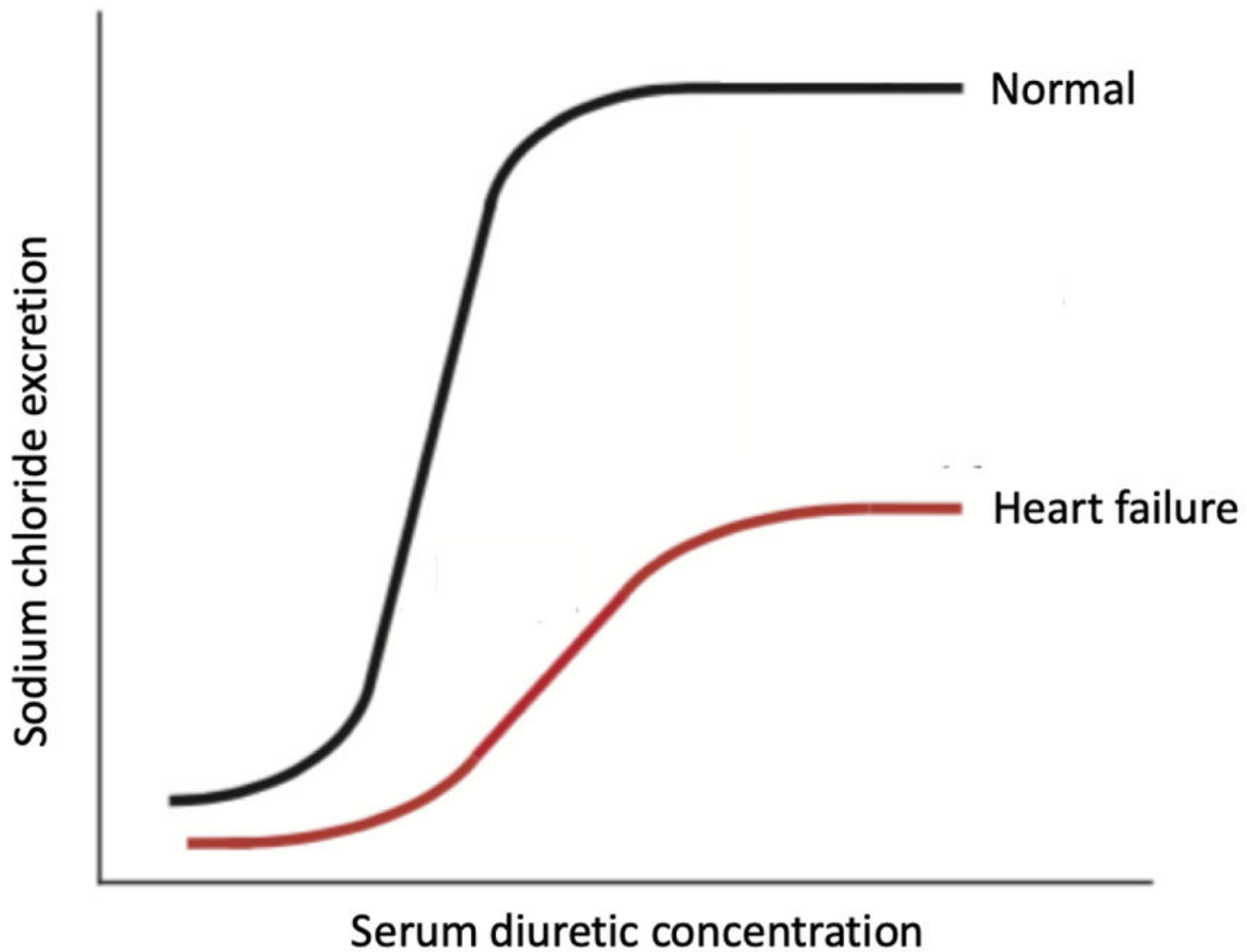

Fig 2.

Dose-response curve for loop diuretics with sodium chloride excretion as a function of plasma loop diuretic concentration. Note a rightward shift in the curve due to diuretic resistance in a patient with chronic heart failure compared to normal subjects. In heart failure, large increases in diuretic dose are required to achieve modest increases in sodium chloride excretion. 
Table 1:

Proposed potential causes of diuretic resistance (DR) ${ }^{\dagger}$

\begin{tabular}{|l|l|}
\hline \multirow{4}{*}{ xPRE-NEPHRON DR } & Poor absorption of diuretics due to gut edema \\
\cline { 2 - 3 } & Poor renal blood flow due to detrimental hemodynamic effects of other conditions such as heart failure or cirrhosis \\
\cline { 2 - 3 } & Hypoalbuminemia \\
\cline { 2 - 3 } & Competition for diuretic entry into the nephron by other organic anions/acids \\
\hline & Poor renal blood flow due to nephron loss \\
\cline { 2 - 3 } & Neurohormonal activation \\
\cline { 2 - 3 } & Loop diuretic dose too low or too infrequent, particularly in the setting of decreased glomerular filtration rate \\
\cline { 2 - 3 } & Nephrotoxic or anti-natriuretic drugs (nonsteroidal inflammatory agents, probenecid, etc.) \\
\cline { 2 - 3 } & Defects at the level of the renal tubule \\
\cline { 2 - 3 } & Distal tubular remodeling from prolonged diuretic exposure \\
\cline { 2 - 3 } & Pharmacogenetics-i.e. epithelial sodium channel (ENaC) transporter subtype, etc. and variable expression \\
\hline
\end{tabular}

Note: The relative effects of each of these mechanisms listed remains unclear; some mechanisms, such as renal tubular defects, are likely more important than others. 
Table 2:

Studies to date that have investigated urinary sodium $\left(\mathrm{U}_{\mathrm{Na}}\right)$ measurements as a predictor of clinical outcomes and natriuretic responsiveness

\begin{tabular}{|c|c|c|c|c|}
\hline Study & $\begin{array}{l}\text { Time point of measurement of } \\
\text { urine sample }\end{array}$ & $\mathbf{N}$ & Measurements & Predictive value/outcome \\
\hline \multirow[t]{2}{*}{ Singh, et al 2014} & $\begin{array}{l}\text { Spot sample at steady state during } \\
\text { continuous loop diuretic infusion }\end{array}$ & 52 & $\mathrm{U}_{\mathrm{Na}}<50 \mathrm{mmol}$ & $\begin{array}{l}\text { Less weight loss and decreased net fluid } \\
\text { output over } 24 \text { hours }\end{array}$ \\
\hline & & & $\begin{array}{l}\mathrm{U}_{\mathrm{Na}}: \text { urine furosemide ratio }<2 \\
\mathrm{mmol} / \mathrm{mg}\end{array}$ & Above, and worse clinical outcomes \\
\hline $\begin{array}{l}\text { Ferreira, et al } \\
2016\end{array}$ & $\begin{array}{l}\text { Spot sample on day } 3 \text { of therapy } \\
\text { with loop diuretic }+/- \\
\text { spironolactone }\end{array}$ & 100 & $\begin{array}{l}\mathrm{U}_{\mathrm{Na}}>60 \mathrm{mmol} / \mathrm{L} \text { and } \mathrm{U}_{\mathrm{Na}}: \text { urine } \\
\text { potassium }>2\end{array}$ & Fewer adverse clinical outcomes \\
\hline $\begin{array}{l}\text { Testani, et al } \\
2016\end{array}$ & $\begin{array}{l}1-2 \text { hours after loop diuretic } \\
\text { administration }\end{array}$ & 50 & $\begin{array}{l}\mathrm{U}_{\mathrm{Na}}<60 \mathrm{mmol} / \mathrm{L} \text { cumulative in } \\
6 \text { hours by equation }\end{array}$ & $\begin{array}{l}\text { Worse cumulative 6-hour sodium } \\
\text { output/poor natriuretic response }\end{array}$ \\
\hline Luk, et al 2018 & $\begin{array}{l}1^{\text {st }} \text { urine void after loop diuretic } \\
\text { administration }\end{array}$ & 103 & $\mathrm{U}_{\mathrm{Na}}<60 \mathrm{mmol} / \mathrm{L}$ & More adverse clinical outcomes \\
\hline $\begin{array}{l}\text { Brinkley, et al } \\
2018\end{array}$ & $\begin{array}{l}1^{\text {st }} \text { urine void after loop diuretic } \\
\text { administration }\end{array}$ & 176 & $\mathrm{U}_{\mathrm{Na}}<60 \mathrm{mmol} / \mathrm{L}$ & $\begin{array}{l}\text { Greater rates of } 30 \text {-day hospitalization } \\
\text { or emergency room visit }\end{array}$ \\
\hline $\begin{array}{l}\text { Collins, et al } \\
2018\end{array}$ & $\begin{array}{l}1 \text { hour after loop diuretic } \\
\text { administration }\end{array}$ & 61 & $\mathrm{U}_{\mathrm{Na}}<35 \mathrm{mEq} / \mathrm{L}$ & Worsening heart failure \\
\hline
\end{tabular}

